\title{
Estrategia para fortalecer el perfil de Alfabetización Mediática de Estudiantes y Docentes de Educación Superior
}

\section{A strategy to strengthen the profile of Media Literacy of Higher Education Students and Teachers}

DOI: https://doi.org/10.32870/dse.v0i23.940

\section{Sandra Guadalupe Altamirano Galván*}

\begin{abstract}
Resumen
En este trabajo se describe parte de un proyecto de tesis doctoral en el que se presenta el diseño y la aplicación de un proyecto de intervención para el fortalecimiento del perfil de alfabetización mediática de estudiantes y docentes de educación superior, en la Facultad de Artes de una universidad pública de Nuevo León. El abordaje teórico-metodológico se gestó desde la investigación basada en diseño (IBD), por lo tanto, incluye estrategias de recolección de datos con enfoque cuantitativo y cualitativo. Los resultados destacan el desarrollo y reforzamiento del conocimiento en las diferentes dimensiones de competencias mediáticas incluidas, tales como tecnología, información, políticas TIC, conocimiento y comunicación, a través de las diversas actividades y reflexiones de los participantes en el curso.
\end{abstract}

Palabras clave: alfabetización mediática - competencias digitales - estrategias - tecnología - intervención educativa.

\begin{abstract}
This paper describes part of a doctoral thesis project in which the design and application of an intervention project to strengthen the media literacy profile of higher education students and teachers is presented, in a School of Arts of a Public University in Nuevo León, Mexico. The theoretical-methodological approach was developed from design-based research (IBD) and therefore includes data collection strategies with a quantitative and qualitative approach. The results highlight the development and reinforcement of knowledge in the different dimensions of the media competencies included such as technology, information, ICT policies, knowledge and communication, through the various activities and insights of the participants in the course.
\end{abstract}

Keywords: media literacy - digital skills - strategies - technology - educative intervention.

* Doctora en Educación con acentuación en Comunicación y Tecnología Educativa. Líneas de investigación: Alfabetización mediática, enseñanza del Diseño Gráfico, identidades. Coordinadora de la Licenciatura en Diseño Gráfico, profesora del área editorial y de identidad de licenciatura, y del área de administración y sustentabilidad en la Maestría en Diseño Gráfico, Universidad Autónoma de Nuevo León. México. sandra.altamiranoglv@uanl.edu.mx 


\section{Introducción}

La sociedad del conocimiento se encuentra en evolución constante, las formas de comunicación, de acceso a la información, los procesos educativos, e incluso la manera de socializar, se han visto transformadas con la llegada de las nuevas tecnologías, el uso de nuevos dispositivos electrónicos y el internet. Esto ha provocado que los medios se encuentren inmersos en todos los ámbitos de la vida cotidiana, por lo que es necesaria la incorporación de las competencias mediáticas en los planes curriculares, lo cual "es una reclamación de organismos internacionales como la UNESCO, que desde su Declaración de Grünwald de 1982, incide en la importancia de la educación mediática en un mundo donde los medios son omnipresentes" (González, Gozálvez, Ramírez, 2014).

Dentro del proceso de adaptación a las nuevas formas de interacción, de comunicación y de uso de las tecnologías, se requieren herramientas, conocimientos y habilidades que permitan un desarrollo y comprensión de lo que sucede alrededor; parte de esto, es el enfrentarse a los medios y a la información que surge de ellos, generando la necesidad de que ese encuentro sea consciente, libre y por decisión propia, de manera analítica, crítica y reflexiva, y es ahí donde la educación en medios cumple su objetivo. Sonia Livingstone (2004: 18) define la alfabetización mediática como "la habilidad para accesar, analizar, evaluar y crear mensajes a través de diversos medios".

Hoy en día, se muestra un gran interés de los individuos hacia los medios tecnológicos, pues les ofrecen grandes beneficios tales como mayor comunicación de manera inmediata y fácil acceso a información, ventajas que también se reflejan en la práctica educativa; sin embargo, el uso de los medios en la educación no se limita al dominio físico de la herramienta, sino que requiere de procesos que permitan su aplicación en el aula para llevar al estudiante a un aprendizaje significativo.

Los estudiantes cuentan actualmente con grandes posibilidades respecto a la búsqueda de información gracias al fácil acceso a la misma, sin embargo, en la práctica educativa aún se presentan problemáticas que hacen evidente la carencia de competencias mediáticas, "actualmente hay una escasez alarmante de profesores especializados en medios de comunicación, sin embargo, la educación en medios depende de que los maestros reconozcan el nivel de conocimientos que los estudiantes poseen en el manejo de los medios, al tiempo que reconocen también las limitaciones y que los mismos maestros aborden estos temas" (Buckingham, 2015: 32).

Las capacidades, habilidades y conocimientos que se deben poseer, exigen una transformación en los individuos, es decir, un desarrollo y preparación constante en cuanto a las nuevas competencias requeridas para enfrentarse al mundo digital y al nuevo contexto social. Hobbs y Jensen (2009: 8) mencionan que "los docentes, para alfabetizar mediáticamente deben encontrar formas creativas de cambiar la práctica educativa para aumentar el conocimiento y las habilidades mediáticas de cada estudiante".

Diólo@os 
Como parte de la tesis doctoral de la que forma parte este artículo, se determinó el perfil de alfabetización mediática de estudiantes y docentes de la institución en la cual se desarrolla esta investigación; en los resultados se obtuvieron debilidades y, considerando lo anterior, en este estudio presentamos la experiencia del diseño e implementación de un proyecto de intervención a través de un curso, como estrategia para fortalecer dichos perfiles. Las preguntas de investigación que orientaron el desarrollo del estudio fueron: ¿Cuáles teorías y estudios podrían ser parte de un curso de alfabetización mediática para estudiantes y docentes de educación superior? ¿De qué manera un proyecto de intervención en educación superior permite fortalecer el perfil de alfabetización mediática de estudiantes y docentes? A continuación se profundiza en los rasgos teóricos y las características metodológicas de esta investigación.

\section{Marco teórico que rige la intervención}

Según la UNESCO (2011: 16), potenciar la competencia mediática contribuye a "empoderar a las personas en todos los ámbitos de la vida para buscar, evaluar, utilizar y crear la información de una forma eficaz para alcanzar sus metas personales, sociales, ocupacionales y educativas" (González, Gozálvez, Ramírez, 2014: 3). La alfabetización mediática, implica "también el conocimiento y capacidad para indagar en las viejas y nuevas fuentes de información, en el aprendizaje de las formas de participación en las redes sociales y en contextos virtuales que implican juegos, simulaciones, etc." (González, 2012: 28).

El contexto del Estatuto Europeo para la Alfabetización Mediática (véase Hug, 2013: 5) describe explícitamente que los individuos alfabetizados en medios deberían ser capaces de utilizar tecnologías de medios efectivamente, ganar acceso hacia los medios, entender cómo y por qué el contenido de los medios es producido, analizar críticamente el mensaje de los medios, utilizar los medios creativamente, evitar el contenido mediático ofensivo o dañino y hacer uso efectivo de los medios respecto a derechos democráticos.

Duncan (1989) considera que el cuerpo teórico de la alfabetización mediática se sustenta en cinco principios, los cuales se mencionan a continuación:

1. Los mensajes se construyen.

2. Los mensajes son representaciones de la realidad con puntos de vista que responden a un determinado contexto cultural.

3. Cada medio de comunicación utiliza su propio conjunto de reglas para elaborar los mensajes.

4. Las personas interpretan los mensajes de los medios de comunicación y les asignan significados según su experiencia personal.

5. Los medios de comunicación son en su mayoría organizaciones con fines de lucro que funcionan en un contexto político-económico. 
“Los ciudadanos han contado con pocas experiencias académicas curriculares en su formación, relacionadas con competencia mediática, a pesar de la presencia masiva de los medios de comunicación en todos los ámbitos del ambiente de nuestra vida personal y social" (Latorre, 2013: 12).

La alfabetización mediática no ha sido un tema primordial en los sistemas educativos y como resultado, no se ha visto reflejado directamente en los planes de estudio, ha faltado su inclusión, pero además ha faltado la preparación de los docentes para que puedan trasmitir ese conocimiento de manera adecuada a los estudiantes.

La UNESCO (2011) menciona que es importante garantizar que los profesores tengan una alfabetización mediática e informacional íntegra, es clave en su tarea de empoderar a los estudiantes en sus esfuerzos para 'aprender a aprender' de una forma autónoma para que puedan continuar con el aprendizaje a lo largo de toda la vida. Con ello, los profesores estarían desempeñando su primer papel como defensores de una ciudadanía informada y racional, y en segundo lugar, estarían respondiendo a los cambios en su papel de educadores, a medida que la enseñanza evoluciona desde haber estado centrada en el profesor hacia una educación que se vuelve más centrada en el estudiante (González, Gozálvez y Ramírez, 2014: 3).

El docente es pieza clave para la preparación y el desarrollo de competencias mediáticas en los estudiantes. Mientras el docente posea dichas competencias y sea consciente del nivel de importancia que la alfabetización mediática tiene para que los individuos puedan enfrentarse a los medios tecnológicos de información, podrá preparar a sus estudiantes de manera integral.

El Ministerio de Educación de Ontario (Canadá) menciona que: con la alfabetización mediática se pretende que los estudiantes desarrollen una comprensión razonada y crítica de la naturaleza de los medios de comunicación de masas, de las técnicas que utilizan y de los efectos que estas técnicas producen. Más en concreto, se trata de una educación que se propone incrementar la comprensión y el disfrute de los alumnos al estudiar cómo funcionan los medios, cómo crean significado, cómo están organizados y cómo construyen su propia realidad. La alfabetización mediática tiene también como objetivo desarrollar en los estudiantes la capacidad de crear productos mediáticos (Media Literacy Resource Guide, Ministry of Education Ontario, 1989, en Gutiérrez, Tyner, 2012: 3).

La alfabetización mediática es un punto clave que debe incluirse en todos los programas educativos y en todos los niveles, puesto que los estudiantes no solamente deben tener acceso a la información, sino estar preparados para enfrentarse a ellos con madurez y actitud crítica.

\section{Marco aplicado}

Como parte de la tesis doctoral de la cual forma parte este artículo, se investigaron las teorías, pensamientos y modelos actuales relacionados con la alfabetización mediática, tales como las 10 dimensiones de Pérez y Delgado (2012), las dimensiones de Celot y Pérez (2009), las dimen- 
siones de Ferrés y Piscitelli (2012) y las incluidas por la UNESCO (2013), y con base en las coincidencias se elaboró un modelo propio al cual se le nombró Modelo de Alfabetización Mediática para Estudiantes y Docentes de Educación Superior (AMEDES) (Altamirano, 2020). El cual incluye cinco dimensiones de alfabetización mediática: tecnología, información, políticas TIC, conocimiento y comunicación. Dicho modelo se muestra en la figura 1, en donde se presenta la definición propuesta para cada dimensión, así también se presenta el marco teórico que representa cada una de ellas.

Figura 1. Modelo AMEDES

\section{MODELO AMEDES \\ Modelo de Alfabetización Mediática para Estudiantes y Docentes de Educación Superior}

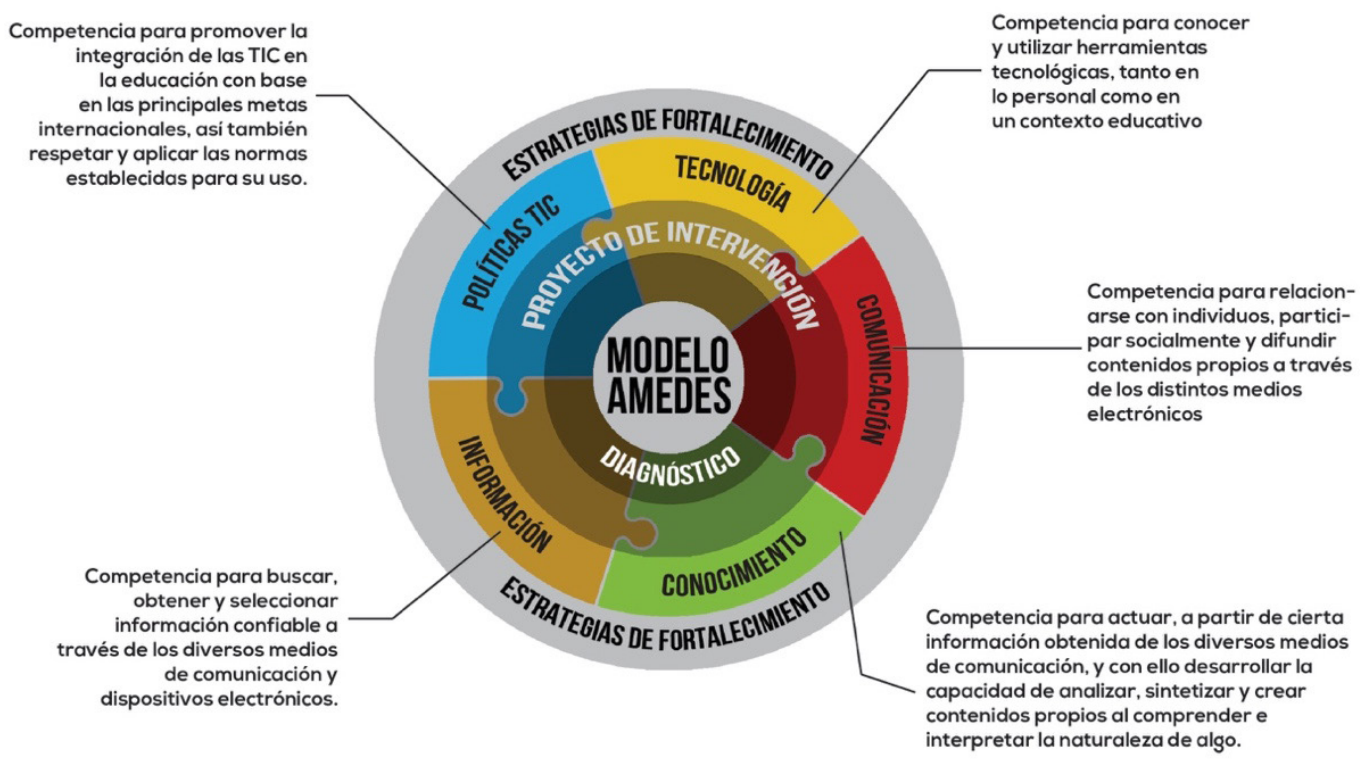

Fuente: Altamirano (2020) Modelo AMEDES.

\section{1) Dimensión Tecnología}

Las TIC son tecnologías de la información y comunicación creadas a partir de la investigación científica y "permiten el acceso, producción, tratamiento y comunicación de información presentada en diferentes códigos, tales como texto, imagen y sonido" (Belloch, 2013).

La inclusión de las TIC en la educación no ha sido la excepción y cada vez se encuentran más inmersas en la práctica educativa, "el uso de las TIC es fundamental para el proceso de en- 
señanza-aprendizaje en la actualidad y es lo que ha ido cambiando el concepto de la sociedad del conocimiento" (García, Camacho, Ancona, 2012: 92).

Los criterios pedagógicos para la selección de una herramienta TIC en la educación, según Monsalve y Valderrama (2016) son los siguientes:

- Participación: a través de comunidades de aprendizaje, compartir conocimientos adquiridos entre usuarios y trabajo colaborativo.

- Interacción: navegar e interactuar con el contenido presentado [...] de forma dinámica, amigable e interactiva.

- Creación de contenidos: diseño de materiales para contrastar contenidos [...] para cualquier tipo de persona.

- Acceso a la información: acceder a la información a través de diferentes sentidos (visual y auditivo) y [...] diferentes dispositivos.

- Evaluación y seguimiento al usuario: estrategias de evaluación que lleven al estudiante a reflexionar sobre su proceso de aprendizaje.

- Criterios técnicos: funcionalidad, autoría, portabilidad, usabilidad, soporte técnico y mantenimiento de la herramienta a evaluar.

\section{2) Dimensión Información}

La información son todos aquellos datos, ya sea textuales, sonoros o imágenes, que se comunican a través de un individuo o de un medio como fuente principal. Según la UNESCO (2005: 19) "la información es un instrumento del conocimiento, pero no es el conocimiento en sí".

Existen diferentes formas para buscar información en la red. Maglione y Varlotta (2009: 14) proponen diferentes técnicas para ello, las cuales son el uso del lenguaje natural, las frases literales, la asociación de palabras clave, los términos requeridos y términos excluidos, los comodines, la búsqueda avanzada, las mayúsculas y minúsculas, el uso de tildes y la combinación de los términos de búsqueda.

La forma más básica de tener información adecuada y valiosa es usar información previamente evaluada, es decir, información científica en el pleno sentido de la expresión, editada, validada, acreditada por comunidades y organismos académicos y científicos, como los siguientes: libros científico-técnicos, revistas y artículos científico-técnicos, publicaciones de congresos, tesis y trabajos académicos, normas técnicas, informes técnicos, patentes, legislación, estadísticas e información empresarial y documentación original, entre otros (Armada, Chasco, Cué, Gómez, Mata, 2012: 13).

Maglione y Varlotta (2009: 18) sugieren algunos criterios para la evaluación de sitios, recursos educativos e información en internet, por lo que los indicadores que se proponen para esto son:

Diálo oos 
- Autoridad: se refiere al responsable del sitio, ya sea una persona, un grupo de personas, una asociación, una institución pública, una institución educativa.

- Selección de contenidos: sirve para evaluar si la selección de contenidos y su tratamiento son adecuados.

- Actualización: se refiere a la incorporación periódica de nueva información, o a la modificación de datos existentes, de acuerdo con los avances teórico-científicos.

- Navegabilidad: facilidad para desplazarse en una página web.

- Organización: si contiene información confiable y si respeta ciertos parámetros y criterios propios del campo académico.

- Legibilidad: combinación de colores, tamaños y tipos de letras, por las características de los fondos, la utilización del espacio, etcétera.

- Adecuación al destinatario: cuando la evaluación de la información o de una página se realiza para ser utilizada como recurso pedagógico, es fundamental considerar su adecuación a la edad de los destinatarios.

\section{3) Dimensión Políticas TIC}

El acceso y las libertades individuales son actualmente para la sociedad civil las dos grandes áreas de interés relativas a las políticas TIC. El acceso tiene que ver con hacer posible el que todos puedan usar internet y otros medios. La segunda temática, relativa a las libertades individuales, comprende derechos fundamentales como la libertad de expresión, el derecho a la intimidad, el derecho a la comunicación, los derechos de propiedad intelectual, etcétera (APC, 2005: 11).

El diálogo sobre las cuestiones relativas a las políticas mundiales TIC está dominado por cinco organizaciones: la Unión Internacional de Telecomunicaciones, en virtud de su mandato para las telecomunicaciones en el interior del sistema de Naciones Unidas; la Organización Mundial de la Propiedad Intelectual, como responsable del establecimiento de reglamentos que gobiernan la titularidad y los contenidos de internet; la Organización Mundial del Comercio, que establece las reglas del comercio internacional; el Banco Mundial, por los recursos financieros y técnicos que brinda para influir en el desarrollo y el Foro Económico Mundial (WEF, por sus siglas en inglés), por su capacidad para convocar a los ricos y poderosos del planeta (APC, 2005: 67).

Las políticas TIC en la educación favorecen e incentivan el uso de estas en el sistema educativo, beneficiándonos en: formación del profesorado, disponibilidad de contenidos digitales y aplicaciones, creación de redes de apoyo, investigación y desarrollo, promoción de comunidades de práctica (SITEAL, 2014: 40).

El organismo encargado de proteger los derechos de autor en México es el Instituto Nacional del Derecho de Autor (INDAUTOR), que forma parte de la Secretaría de Cultura. Según su página web, el INDAUTOR tiene como misión salvaguardar los derechos autorales, promover su conocimiento en los diversos sectores de la sociedad, fomentar la creatividad y el desarrollo cultural e 
impulsar la cooperación internacional y el intercambio con instituciones encargadas del registro y protección del derecho de autor y derechos conexos.

\section{4) Dimensión Conocimiento}

El conocimiento es aquel que se adquiere a través de un proceso de aprendizaje mediante la comprensión y la relación de la información en diversas situaciones, que llegan a interiorizarse y llevan a la práctica dicho aprendizaje. "El análisis de contenido trata de descubrir los significados de un documento, el propósito es poner de manifiesto los significados, al clasificar y codificar los diferentes elementos en categorías que representen más claramente el sentido del mismo" (Saiz, 2010: 4).

Cuando se analiza la información, es necesario leerla, comprenderla y llegar a explicarla a modo de síntesis; por ello, en la práctica educativa es indispensable la generación de estrategias de enseñanza-aprendizaje que permitan desarrollar esta habilidad en los estudiantes. "Cabe destacar que las técnicas de síntesis fortalecen las competencias científicas y lingüísticotextuales de los alumnos. Por lo que es fundamental que los docentes trabajen en el fortalecimiento de esta habilidad básica de comunicación" (Martínez, 2014: 1). Una vez que el individuo genera el conocimiento interno y profundo, puede ser capaz de crear contenidos propios pues ya no solamente ha adquirido la información, sino que además es fuente de esta.

\section{5) Dimensión Comunicación}

La comunicación es fundamental en el desarrollo social de todo individuo, conlleva un proceso particular de relación emisor-receptor cuya finalidad es la de compartir información. Según Caldevilla (2010: 55), de la interactividad propia del medio nace la actual ventaja o desventaja de poder generar cambios de conducta, crear nuevos movimientos de opinión, promover manifestaciones, crear grupos de apoyo o causas concretas, o conseguir crear una moda que genere el consumo de un determinado producto.

En la actualidad, las relaciones entre los seres humanos tienen un nuevo espacio donde generarse, nuevos espacios de intercambios informativos (Cornejo, Tapia, 2012: 221). Actualmente, existen diferentes medios de comunicación que se han formado a partir de las nuevas tecnologías que vinieron a cambiar la perspectiva de la convivencia y comunicación entre individuos. Existen diversas redes sociales, aplicaciones de chat, correo electrónico, videollamadas, entre muchos otros. Sin embargo, "la creciente producción de estos entornos margina el sentido comunicativo de cada medio, haciendo necesario que se proyecte su función comunicativa a través del estudio de su capacidad expresiva y aportando un sentido de uso para la articulación del discurso multimodal" (Labrada, 2015: 2).

Diálo@os 


\section{Aproximación metodológica}

El presente estudio tiene un enfoque mixto unido a la Investigación Basada en Diseño (IBD), por lo tanto, incluye estrategias de recolección de datos con enfoque cuantitativo y cualitativo. En este artículo nos enfocamos en la Fase 1: Elaboración del Diseño Instructivo, en la Fase 2: Implementación del Proyecto de Diseño, así como en la Fase 3: Análisis de los Datos. Estas fases se muestran en la figura 1.

El estudio se realizó en la Licenciatura en Diseño Gráfico de la Facultad de Artes en una universidad pública ubicada en la ciudad de Monterrey, Nuevo León (México). En el proyecto de intervención participaron 319 estudiantes y 16 docentes, se realizó registro de observaciones y notas acerca del desarrollo del curso, se evaluó por puntaje el perfil de alfabetización mediática de los participantes; además, se aplicó una encuesta de cierre para conocer su grado de satisfacción.

Figura 1. Representación de las Fases de la Investigación Basada en Diseño (BID), en el presente estudio

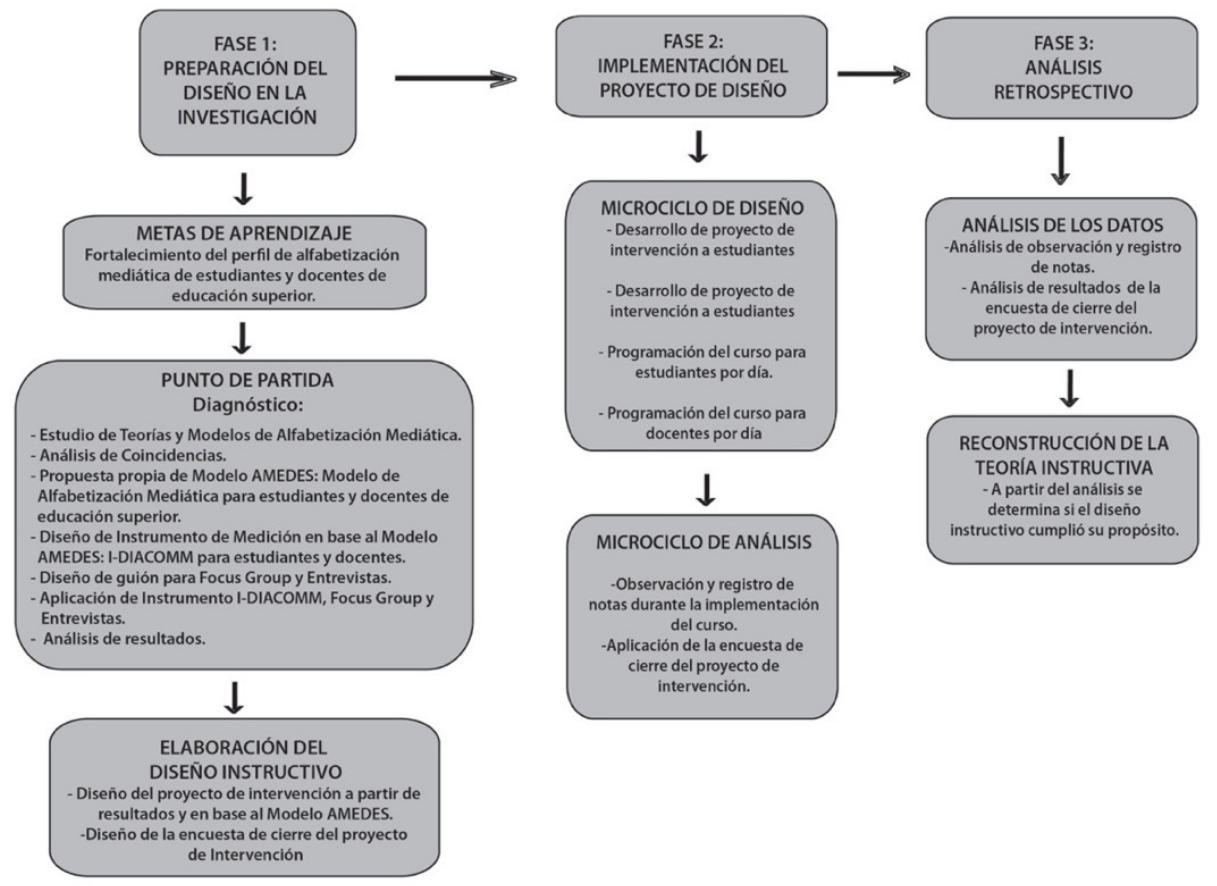

Fuente: creación propia.

\section{Preparación del diseño en la investigación}

Elaboración del diseño instructivo

El proyecto de intervención fue diseñado con base en en el Modelo AMEDES (Altamirano, 2020). A partir de los resultados del instrumento I-DIACOMM, creado con base en dicho modelo y apli- 
cado a estudiantes y docentes de educación superior, se determinó el propósito del curso, el cual consiste en desarrollar en el individuo las competencias mediáticas necesarias para enfrentarse a los medios, desde lo instrumental hasta la capacidad crítica y reflexiva, reconociendo ampliamente la función de los medios, las nuevas tecnologías, la búsqueda eficiente de información, para su uso, comprensión, creación y difusión tanto en el ámbito personal como profesional y académico.

El curso-taller está diseñado con base en la perspectiva constructivista, pues se generan actividades dentro de un proceso práctico, participativo e interactivo; inicia con una presentación general, para luego continuar con una introducción en donde se definen los conceptos de alfabetización mediática y de competencias mediáticas; se introduce el tema con un poco de historia y teoría de la alfabetización mediática a través del tiempo, y de su situación en México.

Se hace mención también de la importancia de la alfabetización mediática en la actualidad y de su papel en la educación. Continúa con una explicación teórica de cada una de las dimensiones, para dar paso a diversas actividades que permitan a los asistentes al curso entender de una mejor manera las dimensiones. Para la realización de las actividades, se les entregó a los asistentes un cuadernillo con instrucciones específicas para que ahí mismo pudieran resolver cada una de ellas.

Tabla 1. Estructura general del Curso-Taller de Alfabetización Mediática

\begin{tabular}{|c|c|c|}
\hline \multicolumn{3}{|c|}{$\begin{array}{l}\text { DIMENSIÓNTECNOLOGÍA: capacidad para conocer y utilizar herramientas tecnológicas, tanto en lo } \\
\text { personal como en un contexto educativo. }\end{array}$} \\
\hline Ejes de la intervención & Nombre de las sesiones & Actividad y evidencia \\
\hline 1. Uso de herramientas digitales & $\begin{array}{l}\text { Criterios pedagógicos para la selec- } \\
\text { ción de una herramienta TIC en la } \\
\text { educación, según Monsalve y Valde- } \\
\text { rrama (2016). }\end{array}$ & $\begin{array}{l}\text { Cuestionario de conocimientos de he- } \\
\text { rramientas digitales, mediante el uso de } \\
\text { Herramienta Digital Interactiva Kahoot! }\end{array}$ \\
\hline $\begin{array}{l}\text { 2. Reflexión sobre uso de herra- } \\
\text { mientas en clase }\end{array}$ & $\begin{array}{l}\text { Reflexionemos: identificar el uso de la } \\
\text { tecnología en las unidades de apren- } \\
\text { dizaje. }\end{array}$ & $\begin{array}{l}\text { Reflexión en el cuadernillo sobre las } \\
\text { herramientas tecnológicas usadas en el } \\
\text { aula y fuera del aula. }\end{array}$ \\
\hline $\begin{array}{l}\text { 3. Planificación de estrategias de } \\
\text { enseñanza-aprendizaje }\end{array}$ & $\begin{array}{l}\text { Pasemos a la acción: promueve la } \\
\text { descripción de una problemática que } \\
\text { puede ser solucionada con herramien- } \\
\text { tas tecnológicas. }\end{array}$ & $\begin{array}{l}\text { Planificación con diversas estrategias } \\
\text { de enseñanza-aprendizaje, en la que se } \\
\text { incluyan herramientas tecnológicas y } \\
\text { piensen ¿qué herramientas utilizarían y } \\
\text { por qué? }\end{array}$ \\
\hline $\begin{array}{l}\text { 4. Búsqueda de herramientas } \\
\text { para clase }\end{array}$ & $\begin{array}{l}\text { Indaguemos: Investigar e identificar } \\
\text { herramientas aplicables en el aula. }\end{array}$ & $\begin{array}{l}\text { Realizar una lista de nuevas herramien- } \\
\text { tas tecnológicas, interactivas, multi- } \\
\text { media, incluyendo juegos digitales, } \\
\text { elementos que podrían utilizar al dar o } \\
\text { tomar una clase específica en un grupo. }\end{array}$ \\
\hline
\end{tabular}




\begin{tabular}{|c|c|c|}
\hline \multicolumn{3}{|c|}{$\begin{array}{l}\text { DIMENSIÓN INFORMACIÓN: capacidad para buscar, obtener y seleccionar información confiable a } \\
\text { través de los diversos medios de comunicación y dispositivos electrónicos. }\end{array}$} \\
\hline $\begin{array}{l}\text { 1. Estrategias para armar claves } \\
\text { de búsqueda }\end{array}$ & $\begin{array}{l}\text { ¿Cómo armar claves de búsqueda?, } \\
\text { según los autores Maglione y Varlotta } \\
\text { (2009). }\end{array}$ & $\begin{array}{l}\text { Indagar en la web armando claves de } \\
\text { búsqueda específicas, según lo visto } \\
\text { en clase, y con ello, tomar nota de los } \\
\text { resultados. }\end{array}$ \\
\hline $\begin{array}{l}\text { 2. Reflexión sobre la importancia } \\
\text { de realizar búsquedas específicas }\end{array}$ & $\begin{array}{l}\text { Reflexionemos: sobre los resultados al } \\
\text { realizar búsquedas específicas. }\end{array}$ & $\begin{array}{l}\text { Reflexión en el cuadernillo sobre los re- } \\
\text { sultados obtenidos en la actividad ante- } \\
\text { rior, a través de una serie de preguntas } \\
\text { sobre la efectividad y la fiabilidad de la } \\
\text { búsqueda. }\end{array}$ \\
\hline $\begin{array}{l}\text { 3. Criterios para evaluar un sitio } \\
\text { web }\end{array}$ & $\begin{array}{l}\text { Evaluando sitios: criterios e indica- } \\
\text { dores para evaluar un sitio, según los } \\
\text { autores Maglione y Varlotta (2009). }\end{array}$ & $\begin{array}{l}\text { Análisis y evaluación de sitios a través } \\
\text { de los indicadores: autoridad, selección } \\
\text { de contenidos, actualización, navegabi- } \\
\text { lidad, organización, legibilidad, adecua- } \\
\text { ción al destinatario. }\end{array}$ \\
\hline $\begin{array}{l}\text { 4. Reflexión sobre la información } \\
\text { encontrada en sitios web }\end{array}$ & $\begin{array}{l}\text { Reflexionemos: identificación de cri- } \\
\text { terios e indicadores en los sitios web } \\
\text { analizados. }\end{array}$ & $\begin{array}{l}\text { En equipos, se realiza el análisis de cada } \\
\text { indicador registrando y fundamentando } \\
\text { sus conclusiones, para determinar la } \\
\text { confiabilidad de una o varias páginas. }\end{array}$ \\
\hline \multicolumn{3}{|c|}{$\begin{array}{l}\text { DIMENSIÓN POLIITICAS TIC: capacidad para promover la integración de las TIC en la educación, con } \\
\text { base en las principales metas internacionales, así también respetar y aplicar las normas establecidas } \\
\text { para su uso. }\end{array}$} \\
\hline $\begin{array}{l}\text { Organismos involucrados en } \\
\text { políticas TIC }\end{array}$ & $\begin{array}{l}\text { Acceso, libertades y derechos funda- } \\
\text { mentales de acceso a la información. }\end{array}$ & $\begin{array}{l}\text { Discusión en clase sobre el tema. } \\
\text { Evaluar el papel de los medios de comu- } \\
\text { nicación de la comunidad. } \\
\text { Propiedad y control de las mayores } \\
\text { empresas de los medios. }\end{array}$ \\
\hline El respeto a los derechos de autor & $\begin{array}{l}\text { El plagio: identificar aspectos de res- } \\
\text { peto al derecho de autor, citación. }\end{array}$ & $\begin{array}{l}\text { Uso de herramienta digital para identifi- } \\
\text { car el plagio. } \\
\text { Uso de formato APA. }\end{array}$ \\
\hline $\begin{array}{l}\text { Relación de los derechos de autor } \\
\text { con la profesión }\end{array}$ & $\begin{array}{l}\text { Reflexionemos: ¿Cómo se relaciona mi } \\
\text { profesión con este tema? }\end{array}$ & $\begin{array}{l}\text { Reflexión en el cuadernillo sobre ejem- } \\
\text { plos de su trabajo y la facilidad que se } \\
\text { tiene de copiar información de otra } \\
\text { persona, llevándolos a hacer conciencia } \\
\text { de no hacer lo que no nos gustaría que } \\
\text { nos hicieran. }\end{array}$ \\
\hline $\begin{array}{l}\text { Reglamentos en uso de TIC Y } \\
\text { derechos de autor }\end{array}$ & $\begin{array}{l}\text { Los reglamentos en tu institución: } \\
\text { identificar las normas de uso de las TIC } \\
\text { y derechos de autor. }\end{array}$ & $\begin{array}{l}\text { Investigación de leyes vigentes en Mé- } \\
\text { xico que regulan la propiedad y control } \\
\text { de medios. } \\
\text { Investigación sobre los reglamentos de } \\
\text { la institución acerca del uso de las TIC y } \\
\text { de los derechos de autor. }\end{array}$ \\
\hline
\end{tabular}




\begin{tabular}{|c|c|c|}
\hline \multicolumn{3}{|c|}{$\begin{array}{l}\text { DIMENSIÓN CONOCIMIENTO: capacidad para actuar a partir de cierta información obtenida de los } \\
\text { diversos medios de comunicación, y con ello desarrollar la capacidad de analizar, sintetizar y crear } \\
\text { contenidos propios al comprender e interpretar la naturaleza de algo. }\end{array}$} \\
\hline $\begin{array}{l}\text { Análisis, síntesis y comprensión } \\
\text { de información }\end{array}$ & $\begin{array}{l}\text { La importancia del análisis y la sínte- } \\
\text { sis de la información, para llegar a la } \\
\text { reflexión y a la crítica personal, y ge- } \\
\text { nerar el conocimiento. }\end{array}$ & $\begin{array}{l}\text { Reflexión: Ubicar alguna evidencia en la } \\
\text { cual se requiera investigación y búsque- } \\
\text { da de información, para determinar qué } \\
\text { estrategias se han utilizado para anali- } \\
\text { zar, comprender, reflexionar y generar } \\
\text { una crítica personal de la información, } \\
\text { y cómo se podían mejorar estas estra- } \\
\text { tegias. }\end{array}$ \\
\hline $\begin{array}{l}\text { Análisis de información de varias } \\
\text { fuentes }\end{array}$ & $\begin{array}{l}\text { La postura del autor de la informa- } \\
\text { ción: la importancia de conocer la } \\
\text { opinión de diversos autores respecto } \\
\text { al tema analizado, para tener una } \\
\text { perspectiva mayor de los datos. }\end{array}$ & Reflexión en cuadernillo sobre el tema. \\
\hline $\begin{array}{l}\text { Importancia de la investigación } \\
\text { en varias fuentes }\end{array}$ & $\begin{array}{l}\text { Análisis de noticias: identificar dife- } \\
\text { rencias en la redacción, información y } \\
\text { especificidad de datos. }\end{array}$ & $\begin{array}{l}\text { Análisis de dos piezas de noticias de } \\
\text { medios diferentes, pero del mismo } \\
\text { tema, identificando elementos clave en } \\
\text { redacción y datos, para su fiabilidad y } \\
\text { objetividad. }\end{array}$ \\
\hline $\begin{array}{l}\text { Subjetividad / objetividad de la } \\
\text { información }\end{array}$ & $\begin{array}{l}\text { Reflexionemos: sobre la subjetividad y } \\
\text { objetividad de los datos. }\end{array}$ & $\begin{array}{l}\text { Reflexión mediante la cual los parti- } \\
\text { cipantes analizan la subjetividad y la } \\
\text { objetividad presentes en las piezas } \\
\text { noticiosas, y hacen conciencia de la im- } \\
\text { portancia de analizar y saber seleccionar } \\
\text { la información adecuadamente. }\end{array}$ \\
\hline \multicolumn{3}{|c|}{$\begin{array}{l}\text { DIMENSIÓN COMUNICACIÓN: capacidad para relacionarse con individuos, participar socialmente y } \\
\text { difundir contenidos propios a través de los distintos medios electrónicos. }\end{array}$} \\
\hline $\begin{array}{l}\text { Importancia de la interacción a } \\
\text { través de medios digitales }\end{array}$ & $\begin{array}{l}\text { ¿Qué es la comunicación? Evolución } \\
\text { de los medios hacia la era digital. }\end{array}$ & Discusión en clase sobre el tema. \\
\hline $\begin{array}{l}\text { Análisis de los creadores de infor- } \\
\text { mación actuales }\end{array}$ & $\begin{array}{l}\text { Creadores de información: ¿qué son } \\
\text { los youtubers, influencers, bloggers? }\end{array}$ & $\begin{array}{l}\text { Realizar una lista de youtubers o influen- } \\
\text { cers que han conocido y qué es lo que } \\
\text { comparten. } \\
\text { Reflexionar sobre la fiabilidad de dichos } \\
\text { contenidos. }\end{array}$ \\
\hline Importancia de ser prosumidores & $\begin{array}{l}\text { ¿Qué es un prosumidor? la } \\
\text { importancia de la creación y difusión } \\
\text { de contenido. }\end{array}$ & $\begin{array}{l}\text { Describir en el cuadernillo, con base en } \\
\text { el conocimiento individual, ¿qué podría } \\
\text { trasmitir cada uno de los participantes a } \\
\text { través de la creación de contenido? }\end{array}$ \\
\hline $\begin{array}{l}\text { Planificación / creación de conte- } \\
\text { nido mediático. }\end{array}$ & ¿Cómo crear contenido mediático? & $\begin{array}{l}\text { Planeación de la creación de un produc- } \\
\text { to mediático utilizando herramientas } \\
\text { investigadas en la dimensión Tecnolo- } \\
\text { gía, y presentar dicho producto como } \\
\text { cierre del curso. }\end{array}$ \\
\hline
\end{tabular}

Fuente: Creación propia. 


\section{Implementación del experimento de diseño: Microciclo de diseño}

\section{Desarrollo del proyecto de intervención con estudiantes}

El curso para estudiantes se llevó a cabo dividiéndolos en dos grupos, esto debido a la capacidad del espacio y el número de estudiantes. El curso se impartió en seis horas de clase presenciales y seis horas extra-aula, con un total de 12 horas.

El lugar donde se llevó a cabo el curso fue en el auditorio de la facultad, que cuenta con un equipo de cómputo con internet, pantalla y audio. Los estudiantes no tenían equipo de cómputo individual, sin embargo, esto no fue problema debido a que usaron su celular.

Tabla 2. Programación del curso para estudiantes

\begin{tabular}{|c|c|c|c|}
\hline \multicolumn{4}{|c|}{ 1er día } \\
\hline Horario & Competencia & Tipo de Actividad & Tiempo \\
\hline $\begin{array}{l}\text { M 9:00-9:15 } \\
\text { V 12:30-12:45 }\end{array}$ & $\begin{array}{l}\text { PRESENTACIÓN/ } \\
\text { INTRODUCCIÓN }\end{array}$ & & \\
\hline \multirow{4}{*}{$\begin{array}{l}\text { M 9:15-10:15 } \\
\text { V 12:45-13:45 }\end{array}$} & \multirow[t]{4}{*}{ TECNOLOGÍA } & TEORÍA & 25 MINUTOS \\
\hline & & JUEGO & 10 MINUTOS \\
\hline & & ACTIVIDAD 1.1 & 10 MINUTOS \\
\hline & & ACTIVIDAD 1.2 & 15 MINUTOS \\
\hline \multirow{4}{*}{$\begin{array}{l}M 10: 15-11: 15 \\
V_{13}: 45-14: 45\end{array}$} & \multirow[t]{4}{*}{ INFORMACIÓN } & TEORIA & 30 MINUTOS \\
\hline & & ACTIVIDAD 2.1 & 15 MINUTOS \\
\hline & & ACTIVIDAD 2.2 & 15 MINUTOS \\
\hline & & TEORÍA & 30 MINUTOS \\
\hline \multirow{4}{*}{$\begin{array}{l}M_{11: 15}-12: 00 \\
V_{14: 45}-15: 30\end{array}$} & \multirow[t]{4}{*}{ POLÍTICASTIC } & ACTIVIDAD 3.1 & 15 MINUTOS \\
\hline & & TEORÍA & 25 MINUTOS \\
\hline & & JUEGO & 10 MINUTOS \\
\hline & & ACTIVIDAD 1.1 & 10 MINUTOS \\
\hline \multicolumn{4}{|c|}{ 2do día } \\
\hline $\begin{array}{l}\text { M 9:00 - 9:15 } \\
\text { V 12:30-12:45 }\end{array}$ & $\begin{array}{l}\text { REPASO / REVISIÓN ACTIVI- } \\
\text { DADES EXTRA-AULA }\end{array}$ & TEORÍA & 30 MINUTOS \\
\hline \multirow{3}{*}{$\begin{array}{l}\text { M 9:15-10:30 } \\
\text { V 12:45-14:00 }\end{array}$} & \multirow[t]{3}{*}{ CONOCIMIENTO } & TEORÍA & 30 MINUTOS \\
\hline & & REFLEXIÓN & 10 MINUTOS \\
\hline & & ACTIVIDAD 4.1 & 35 MINUTOS \\
\hline \multirow{2}{*}{$\begin{array}{l}M_{10}: 30-11: 30 \\
V_{14}: 00-15: 00\end{array}$} & \multirow[t]{2}{*}{ COMUNICACIÓN } & TEORÍA & 30 MINUTOS \\
\hline & & ACTIVIDAD 5.1 & 3о MINUTOS \\
\hline $\begin{array}{l}M_{11}: 30-12: 00 \\
V_{15}: 00-15: 30\end{array}$ & ENCUESTA SALIDA & ENCUESTA & 30 MINUTOS \\
\hline
\end{tabular}




\section{Desarrollo del proyecto de intervención con docentes}

El curso para docentes se llevó a cabo en 10 horas presenciales y 10 horas extra-aula, con un total de 20 horas. El lugar donde se realizó el curso era un aula de cómputo que tenía acceso a internet, cada docente y la instructora contaban con su propio equipo, además el aula cuenta con proyector y pantalla.

Tabla 3. Programación del curso a docentes

\begin{tabular}{|c|c|c|c|}
\hline \multicolumn{4}{|c|}{ 1er día } \\
\hline Horario & Competencia & Tipo de Actividad & Tiempo \\
\hline 9:00 - 9:30 & $\begin{array}{l}\text { PRESENTACIÓN/ } \\
\text { INTRODUCCIÓN }\end{array}$ & & \\
\hline \multirow[t]{4}{*}{ 9:30-11:00 } & \multirow[t]{4}{*}{ TECNOLOGÍA } & TEORÍA & 30 MINUTOS \\
\hline & & JUEGO & 20 MINUTOS \\
\hline & & ACTIVIDAD 1.1 & 20 MINUTOS \\
\hline & & ACTIVIDAD 1.2 & 20 MINUTOS \\
\hline 11:00-11:30 & INFORMACIÓN & TEORÍA & 30 MINUTOS \\
\hline 11:30-12:00 & BREAK & & \\
\hline \multirow[t]{3}{*}{ 12:00-1:00 } & \multirow[t]{3}{*}{ INFORMACIÓN } & TEORIA & 10 MINUTOS \\
\hline & & ACTIVIDAD 2.1 & 20 MINUTOS \\
\hline & & ACTIVIDAD 2.2 & 30 MINUTOS \\
\hline \multirow[t]{2}{*}{$1: 00-2: 00$} & \multirow[t]{2}{*}{ POLÍTICASTIC } & TEORÍA & 40 MINUTOS \\
\hline & & ACTIVIDAD 3.1 & 20 MINUTOS \\
\hline \multicolumn{4}{|c|}{ 2do día } \\
\hline 9:00 - 9:30 & $\begin{array}{l}\text { REPASO / REVISIÓN ACTI- } \\
\text { VIDADES EXTRA-AULA }\end{array}$ & TEORÍA & 30 MINUTOS \\
\hline \multirow[t]{3}{*}{ 9:30 - 11:30 } & \multirow[t]{3}{*}{ CONOCIMIENTO } & TEORÍA & 50 MINUTOS \\
\hline & & REFLEXIÓN & 10 MINUTOS \\
\hline & & ACTIVIDAD 4.1 & 30 MINUTOS \\
\hline $11: 30-12: 00$ & BREAK & & \\
\hline \multirow[t]{2}{*}{ 12:00-1:30 } & \multirow[t]{2}{*}{ COMUNICACIÓN } & TEORÍA & 30 MINUTOS \\
\hline & & ACTIVIDAD 5.1 & 6o MINUTOS \\
\hline $1: 30-2: 00$ & ENCUESTA SALIDA & ENCUESTA & 30 MINUTOS \\
\hline
\end{tabular}

\section{Microciclo de análisis}

Durante la implementación del proyecto de intervención se realizó el registro de observaciones y notas en cuanto al contenido temático y las actividades con respecto al desarrollo de la clase y

\section{Diálo Dos}


el desempeño de los participantes. Así también, se analizó dicho desempeño a través de las actividades que se realizaron en el cuadernillo. Dicho cuadernillo estaba conformado por las cinco dimensiones que el Modelo AMEDES propone, cada dimensión contaba con cuatro actividades, las cuales tenían un valor de 5 puntos cada una, es decir, 20 puntos por dimensión, que dan un total de 100 puntos. Para valorar el perfil de los participantes en el curso una vez concluido, se verificaron los aciertos de cada actividad, teniendo una clasificación por puntaje para determinar el perfil por cada dimensión. Esto se muestra en la tabla 4.

Tabla 4. Perfiles determinados en cuadernillo de trabajo por dimensión

\begin{tabular}{|l|l|l|}
\hline \multicolumn{1}{|c|}{ PERFIL } & \multicolumn{1}{|c|}{ PUNTAJE } & \multicolumn{1}{c|}{ DEFINICIÓN } \\
\hline ALTO & $16-20$ & Posee el máximo nivel de competencias mediáticas. \\
\hline MEDIO & $11-15$ & $\begin{array}{l}\text { Posee un buen nivel de competencias mediáticas, sin em- } \\
\text { bargo, aún no cuenta con el nivel óptimo para el aprovecha- } \\
\text { miento total de dichas competencias. }\end{array}$ \\
\hline BAJO & $6-10$ & No posee el nivel de competencias mediáticas básicas. \\
\hline MUY BAJO & $1-5$ & Indicio nulo de competencias mediáticas. \\
\hline
\end{tabular}

\section{Análisis retrospectivo}

Una vez que se implementó el curso de alfabetización mediática, se analizaron las observaciones y notas registradas durante el desarrollo del curso, así también las actividades que se realizaron en el cuadernillo. Al finalizar el curso se aplicó, tanto a docentes como estudiantes, un instrumento de ocho preguntas que abarcaban las cinco dimensiones y el concepto de alfabetización mediática; dicho instrumento era una escala Likert de cinco niveles: totalmente de acuerdo, de acuerdo, ni en acuerdo ni en desacuerdo, en desacuerdo y totalmente en desacuerdo. El instrumento iniciaba con una frase que decía, "Una vez que he tomado el curso de Alfabetización Mediática..." y posteriormente los cuestionamientos, esto con el propósito de conocer el grado de satisfacción de los estudiantes con el curso.

\section{Resultados}

A partir de la aplicación del instrumento I-DIACOMM, entrevistas y focus group, se determinó el perfil de alfabetización mediática de estudiantes y docentes de la institución en la cual se desarrolla esta investigación; en los resultados se obtuvo que existen mayores fortalezas en las competencias de tecnología y políticas TIC, pero también mayores debilidades en las competencias de información, conocimiento y comunicación. Los resultados se puede observar en las figuras 3 y 4 . 
Figura 3. Perfil inicial de Alfabetización Mediática de Estudiantes

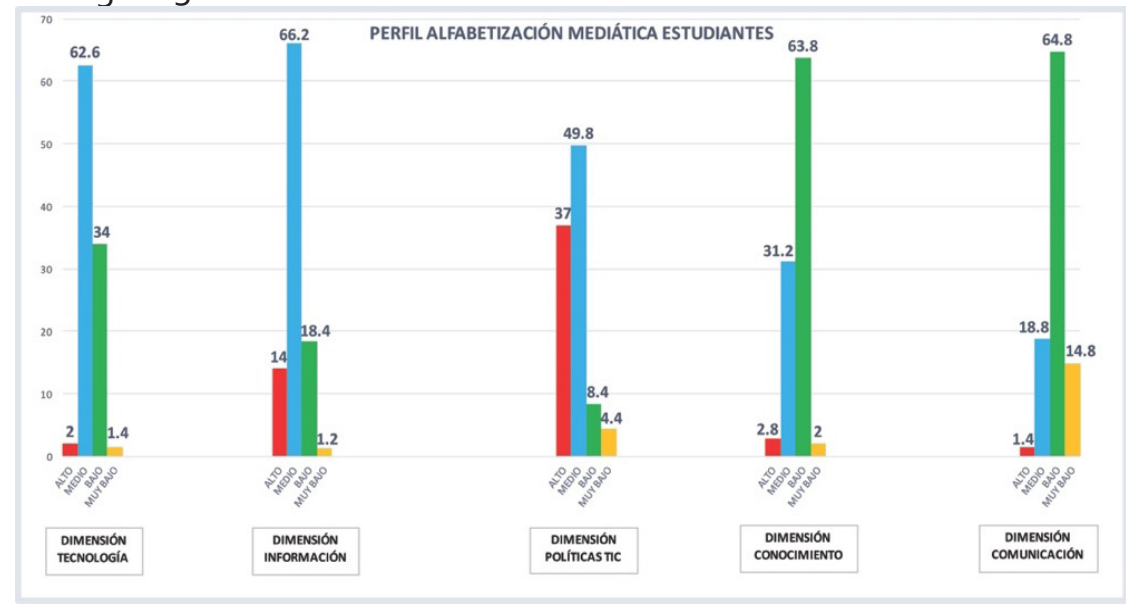

Fuente: Creación Propia.

Fig.4. Perfil inicial de Alfabetización Mediática de Docentes PERFIL ALFABETIZACIÓN MEDIÁTICA DOCENTES

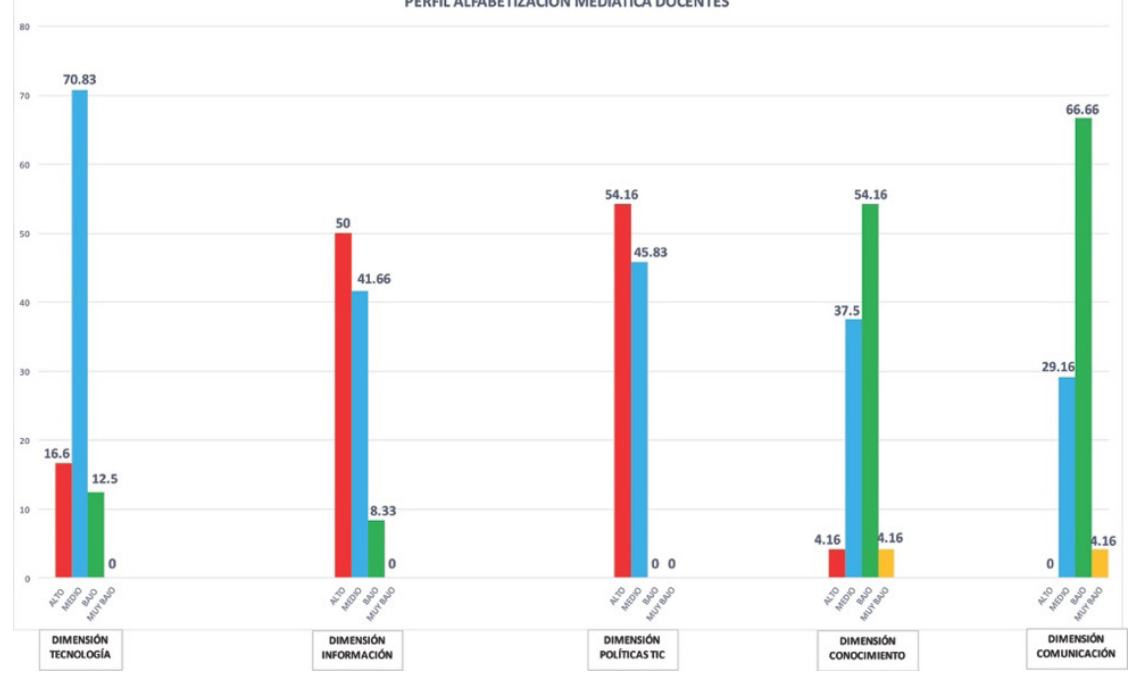

Fuente: Creación Propia.

También se detectó que los estudiantes tenían perfiles más bajos que los docentes, y además, a través de los datos cualitativos, se descubrió que los docentes no trasmiten esos conocimientos a los estudiantes, lo cual traer consecuencias negativas en su desempeño. Cabe mencionar que, aunque en algunas dimensiones obtuvieron puntajes más altos en los resultados cuantitativos, se encontraron debilidades en los datos cualitativos. Ahora bien, los docentes también presentan grandes debilidades en las competencias de conocimiento y comunicación, al igual que los estudiantes, por tanto, puede existir una relación directa de este resultado como 
consecuencia del proceso de enseñanza-aprendizaje. Coinciden también en que los docentes aun no están preparados en este tema, pero es importante que se les prepare para que puedan trasmitir ese conocimiento a los estudiantes; asimismo, consideran que la institución tiene buena infraestructura para incluir el tema en el plan educativo, pero aun no lo suficiente.

\section{Perfiles según el cuadernillo}

Los perfiles se obtuvieron a partir del puntaje obtenido por los participantes en las actividades de cada dimensión del cuadernillo en el proyecto de intervención; los resultados de estudiantes se muestran en la figura 5, mientras que los resultados de docentes se encuentran en la figura 6. Por otro lado, también se tomaron notas y observaciones durante el curso, por lo que se presentan los resultados por dimensión.

Figura 5. Perfil final de Alfabetización Mediática de Estudiantes

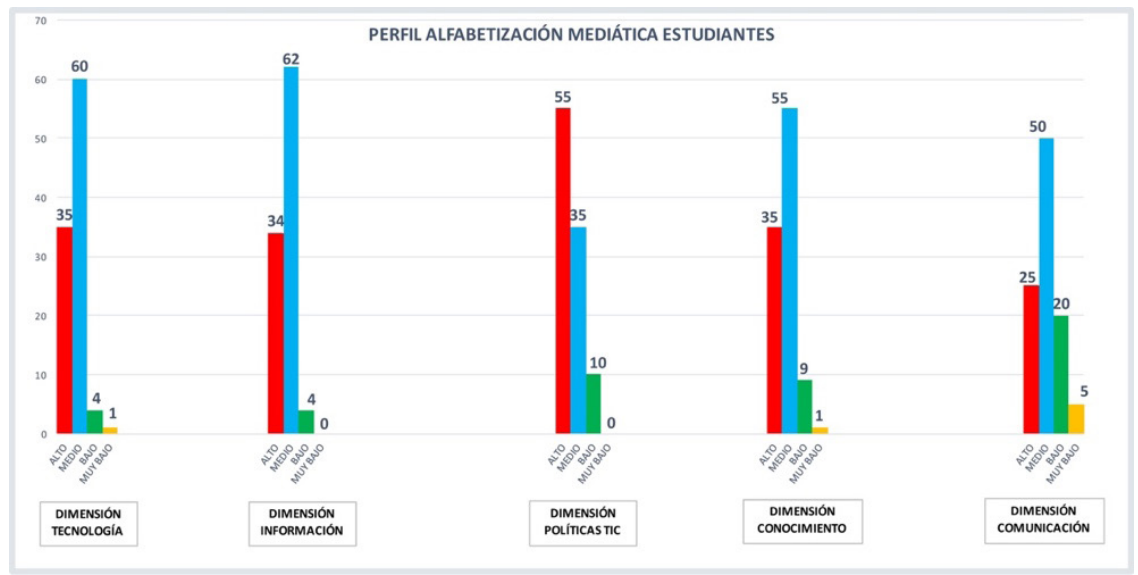

Fuente: Creación Propia.

Fig.6. Perfil final de Alfabetización Mediática de Docentes

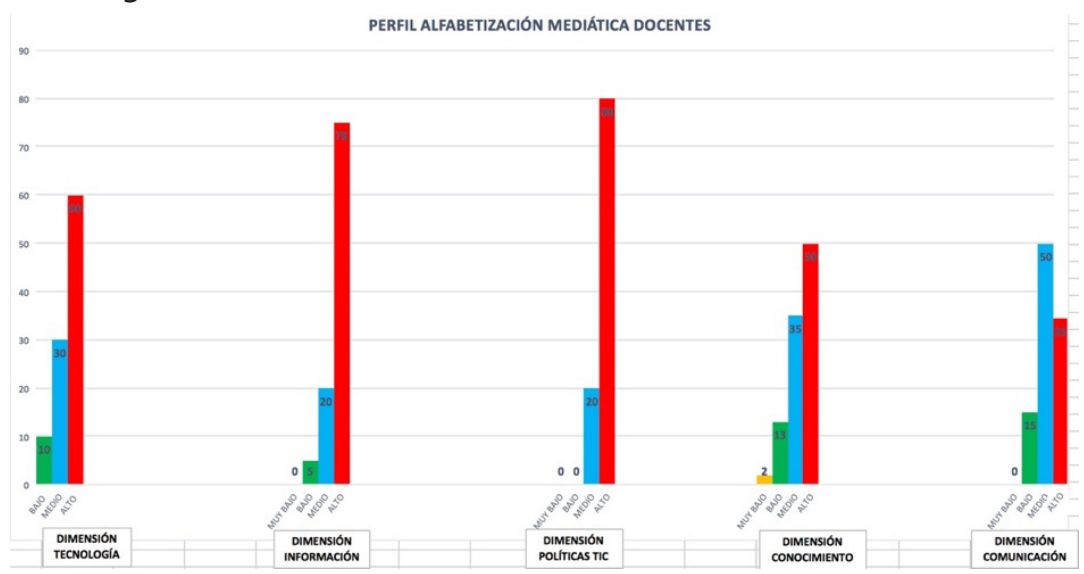

Fuente: Creación Propia. 


\section{1) Dimensión Tecnología}

Entre los estudiantes, $35 \%$ presentaron un perfil alto, mientras que $60 \%$ obtuvo un perfil medio, $4 \%$ bajo y $1 \%$ muy bajo. Los docentes presentaron un perfil alto en $60 \%$, mientras que $30 \%$ obtuvo un perfil medio y $10 \%$ bajo.

En cuanto a las observaciones y notas durante el proyecto de intervención, tanto estudiantes como docentes mostraron gran interés en utilizar herramientas tecnológicas en el proceso de enseñanza-aprendizaje.

- Uso de herramientas digitales: Se generó una gran interacción entre los participantes, diversión, entusiasmo y sorpresa con la herramienta lúdica Kahoot!, y además surgió el interés en usarla en clase.

- Reflexión sobre el uso de herramientas en clase: Mencionaron que utilizan proyector, computadora, presentaciones, pero además hicieron conciencia de que existen más herramientas interactivas que podrían utilizar y aún no lo hacen.

- Planificación de estrategias de enseñanza-aprendizaje: Generaron planificación para mejorar estrategias, mencionando el uso de redes sociales, tutoriales, la nube, google drive, dropbox. Imágenes en 2D y 3D, videollamadas, plataformas para tomar notas en línea y compartir con los participantes de clase.

- Búsqueda de herramientas para clase: Realizaron búsqueda de herramientas tecnológicas usando los criterios pedagógicos vistos en clase, y algunas de las herramientas que encontraron fueron aplicaciones de celular, software para edición de video, plataformas de exámenes en línea y redes sociales.

\section{Encuesta de cierre}

La dimensión tecnología se incluyó a través de dos preguntas que se presentan a continuación:

- Me considero capaz de aprovechar mejor los recursos tecnológicos en mi proceso de enseñanza / aprendizaje

- Me considero capaz de seleccionar el medio adecuado para mi proceso de enseñanza / aprendizaje

Estudiantes: Al primer cuestionamiento, una gran mayoría de la población (98.1\%) respondió entre totalmente de acuerdo y de acuerdo, que son capaces de aprovechar mejor los recursos tecnológicos en su proceso de aprendizaje, mientras que $1.6 \%$ respondió ni en acuerdo ni en desacuerdo, y únicamente $0.3 \%$ dijo estar en desacuerdo.

En cuanto al segundo cuestionamiento, una gran mayoría de la población de estudiantes (96.3\%) respondió entre totalmente de acuerdo y de acuerdo, en cuanto a que son capaces de 
seleccionar el medio adecuado para mi proceso de aprendizaje, mientras que 3.4\% respondió ni en acuerdo ni en desacuerdo y $0.3 \%$ dijo estar en desacuerdo.

Docentes: En cuanto a la primera afirmación, una gran mayoría de los docentes (93.8\%) respondió entre totalmente de acuerdo y de acuerdo, en que son capaces de aprovechar mejor los recursos tecnológicos en su proceso de enseñanza, mientras que $6.3 \%$ dijo que ni en acuerdo ni en desacuerdo.

En cuanto al segundo cuestionamiento, el total de la población de docentes (100\%), mencionó estar totalmente de acuerdo (62.5\%) y de acuerdo (37.5\%) en que se considera capaz de seleccionar el medio adecuado para su proceso de enseñanza.

\section{2) Dimensión Información}

Los estudiantes presentaron un perfil alto en $34 \%$, mientras que $62 \%$ obtuvo un perfil medio y $4 \%$ bajo. Los docentes presentaron un perfil alto en $75 \%$, mientras que $20 \%$ obtuvo un perfil medio y $5 \%$ bajo.

En cuanto a la dimensión información, antes del curso, tanto estudiantes como docentes desconocían estrategias de búsquedas eficientes de información y tampoco conocían criterios para evaluar un sitio confiable/no confiable, así que el curso fue de gran utilidad para ellos.

- Estrategias para armar claves de búsqueda: Se genera el aprendizaje de comandos para hacer búsquedas efectivas y eficientes. Así también se muestra un gran interés, entusiasmo y sorpresa por parte de los participantes en el curso.

- Reflexión sobre la importancia de realizar búsquedas específicas: Antes no habían usado estos comandos y hacen conciencia de los beneficios de usarlos y armar claves de búsqueda.

- Criterios para evaluar un sitio web: Se genera el aprendizaje de criterios para evaluar un sitio web y determinar si es confiable o no lo es.

- Reflexión sobre la información encontrada en sitios web: Se usan criterios de evaluación de sitios web y comentan que antes no evaluaban los sitios, pero de ahora en adelante lo harán. Los docentes mencionan que enseñarán a los alumnos para que lo hagan también.

\section{Encuesta de cierre}

La dimensión información se incluyó a través de dos preguntas que se presentan a continuación:

- Me considero capaz de hacer búsquedas de información más eficientes

- Me considero capaz de identificar sitios confiables / no confiables 
Estudiantes: Con respecto a la primera pregunta, una gran mayoría de la población (94\%) respondió estar totalmente de acuerdo (46.7\%) y de acuerdo (47.3\%) en cuanto a que se considera capaz de hacer búsquedas de información más eficientes, mientras que 5.6\% mencionó no estar en acuerdo ni en desacuerdo y $0.3 \%$ dijo estar en desacuerdo.

En cuanto al segundo cuestionamiento, una gran mayoría de la población de estudiantes (91.5\%) dijo estar totalmente de acuerdo (47.3\%) y de acuerdo (44.2\%) en que se consideran capaces de identificar sitios confiables/no confiables, mientras que $8.5 \%$ no está de acuerdo ni en desacuerdo.

Docentes: Con respecto al primer cuestionamiento, una gran mayoría de la población de docentes (93.8\%) dijo estar totalmente de acuerdo (56.3\%) y de acuerdo (37.5\%) en que se consideran capaces de hacer búsquedas de información más eficientes, mientras que $6.3 \%$ mencionó no estar de acuerdo ni en desacuerdo.

En cuanto a la segunda pregunta, una gran mayoría de los docentes (81.3\%) dijo estar totalmente de acuerdo (50\%) y de acuerdo (31.3\%) en que se consideran capaces de identificar sitios confiables/no confiables, mientras que $12.5 \%$ mencionó estar de acuerdo ni en desacuerdo, mientras que $6.3 \%$ dijo estar en desacuerdo.

\section{3) Dimensión Políticas TIC}

Los estudiantes presentaron un perfil alto en $55 \%$ de los casos, mientras que $35 \%$ obtuvo un perfil medio y $10 \%$ bajo. Los docentes presentaron un perfil alto en $80 \%$ de los casos, mientras que $20 \%$ obtuvo un perfil medio.

En cuanto a la dimensión políticas TIC, al iniciar el curso se detectó que los estudiantes no respetaban los derechos de autor y no lo veían como algo negativo, pero en el momento en que se les explicó, se generó gran polémica entre ellos que propició una conciencia colectiva de la importancia del tema. En cuanto a los docentes, no supieron determinar si existía un reglamento respecto al uso de las TIC en la institución y consideraron fundamental el respeto a los derechos de autor.

- Organismos involucrados en políticas TIC: Desconocían que existían, pero durante el curso obtuvieron el conocimiento acerca de dichos organismos y su importancia en las políticas TIC.

- Reflexión sobre el respeto a los derechos de autor: Los estudiantes afirmaron que copian información sin dar crédito al autor y los docentes confirman que es así, con el curso hacen conciencia de la importancia de respetar los derechos de autor y aprenden a usar una herramienta para detectar plagio.

- Relación de los derechos de autor con la profesión: Los estudiantes hacen conciencia al pensar en su trabajo con respecto al uso de imágenes, ilustraciones, tipografías, etc., mien- 
tras que los docentes hacen conciencia de que deben exigir más al alumno respecto a este tema.

- Reglamentos en uso de TIC y derechos de autor: Se genera conciencia sobre la existencia de reglamentos en cuanto al plagio en la institución. Y sobre la inexistencia de reglamentos de uso de TIC se ve la necesidad de crearlo.

\section{Encuesta de cierre}

La dimensión Políticas TIC se incluyó a través de una pregunta que se presenta a continuación:

- ¿Considero importante la aplicación de Políticas TIC en la educación?

Estudiantes: en esta pregunta, una gran mayoría de la población de estudiantes (95.9\%) dijo estar totalmente de acuerdo (61.4\%) y de acuerdo (34.5\%) en que consideran importante la aplicación de políticas TIC en la educación, mientras $4.1 \%$ mencionó no estar en acuerdo ni en desacuerdo.

Docentes: en este cuestionamiento, el total de la población (100\%) mencionó estar totalmente de acuerdo (68.8\%) y de acuerdo (31.3\%) en que consideran importante la aplicación de Políticas TIC en la educación.

\section{4) Dimensión Conocimiento}

Los estudiantes presentaron un perfil alto en 35\%, mientras que 55\% obtuvo un perfil medio, $9 \%$ bajo y $1 \%$ muy bajo. Los docentes presentaron un perfil alto en $50 \%$, mientras que $35 \%$ obtuvo un perfil medio, $13 \%$ bajo y $2 \%$ muy bajo.

En lo que respecta a la dimensión conocimiento, durante el curso se pudo detectar que los estudiantes se resistían al análisis profundo de la información, pero debido a las estrategias del curso y sus actividades, se logró una buena discusión del tema, llevando a un aprendizaje significativo.

En cuanto a los docentes, fueron conscientes de la información a la cual se enfrentan día a día los estudiantes y que deben saber analizar y seleccionar adecuadamente para no confundirse entre la objetividad de la información y la subjetividad de la postura del autor de la misma, por lo que mostraron mayor interés en poner énfasis en este tema en los proyectos que les encargan a sus estudiantes.

- Análisis, síntesis y comprensión de información: Se hace conciencia de la importancia de analizar, sintetizar y comprender la información. Se reflexionó sobre el uso de estrategias de enseñanza-aprendizaje enfocadas en ello. 
- Análisis de información de varias fuentes: Hacen conciencia de la diferencia de redacción entre varias fuentes, así también detectan la postura del autor y la cantidad/calidad de la información.

- Importancia de la investigación en varias fuentes: Hacen conciencia de que no es suficiente leer una sola fuente para enterarse de la información completa y de la importancia de hacer búsqueda en varias fuentes.

- Subjetividad/objetividad de la información: Hacen conciencia de la existencia de la subjetividad en la redacción de la información y de la importancia de analizar y saber seleccionar la información.

\section{Encuesta de cierre}

La dimensión conocimiento se incluyó a través de una pregunta que se presenta a continuación:

- Me considero capaz de planear la creación de contenido en diversos medios tecnológicos, a partir del análisis, la síntesis y la comprensión de la información.

Estudiantes: con respecto a este cuestionamiento, una gran mayoría de la población de estudiantes (91.3\%) dijo estar totalmente de acuerdo (40.8\%) y de acuerdo (50.5\%) en que se consideran capaces de planear la creación de contenido en diversos medios tecnológicos, a partir del análisis, la síntesis y la comprensión de la información, mientras que 7.8\% mencionó no estar en acuerdo ni en desacuerdo y $0.9 \%$ respondió que estaba en desacuerdo.

Docentes: en cuanto a esta pregunta, del total de la población de docentes $(100 \%)$ respondió estar totalmente de acuerdo (37.5\%) y de acuerdo (62.5\%) en que se consideran capaces de planear la creación de contenido en diversos medios tecnológicos, a partir del análisis, la síntesis y la comprensión de la información.

\section{5) Dimensión Comunicación}

Los estudiantes presentaron un perfil alto en $25 \%$, mientras que $50 \%$ obtuvo un perfil medio, $20 \%$ bajo y $5 \%$ muy bajo. Los docentes presentaron un perfil alto en $35 \%$, mientras que $50 \%$ obtuvo un perfil medio y $15 \%$ bajo.

En cuanto a esta dimensión al iniciar tanto estudiantes como docentes no eran conscientes de que podían crear contenidos propios, al parecer, no se sentían capaces de hacerlo; sin embargo, al explicarles fueron despejando dudas al respecto e iniciar la planeación de su producto mediático sin ningún problema. El curso les permitió crear conciencia en este tema y se mostraron muy interesados en iniciar su camino en la creación de contenido a partir de sus conocimientos. 
- Importancia de interacción a través de medios digitales: Se genera una reflexión sobre la importancia de los medios digitales para la comunicación de hoy en día.

- Análisis de los creadores de información actuales: Hacen conciencia de la existencia de youtubers, influencers, bloggers al crear contenido, analizando el nivel de conocimiento de estas personas para hablar de ciertos temas y tener en cuenta el grado de objetividad con el que hablan.

- Importancia de ser prosumidores: Desconocían el término y hacen conciencia de la importancia de no ser solo consumidores, sino productores de contenido. Se generó interés y entusiasmo para crear productos mediáticos.

- Planificación / Creación de contenido mediático: Planificaron la producción de contenido mediático utilizando diversas herramientas digitales, así como involucrando sus conocimientos y la investigación.

\section{Encuesta de cierre}

La dimensión comunicación se incluyó a través de la siguiente pregunta:

- Me considero capaz de crear contenido y difundirlo a un público mayor, dentro y fuera del contexto escolar.

Estudiantes: en esta pregunta, una gran mayoría de la población de estudiantes (82.4\%) mencionó estar totalmente de acuerdo (40.4\%) y de acuerdo (42\%) en que se consideran capaces de crear contenido y difundirlo al público, mientras que $16.6 \%$ contestó que no estaba ni de acuerdo ni en desacuerdo, $0.6 \%$ mencionó estar en desacuerdo y $0.3 \%$ dijo que totalmente en desacuerdo.

Docentes: en este cuestionamiento, una gran mayoría de la población de docentes (93.8\%) dijeron estar totalmente de acuerdo (31.3\%) y de acuerdo (62.5\%) en que se consideran capaces de crear contenido y difundirlo al público, dentro y fuera del contexto escolar, mientras que $6.3 \%$ contestó ni en acuerdo ni en desacuerdo.

\section{Educación en competencias mediáticas}

Al iniciar el curso se les preguntó, tanto a estudiantes como a docentes, si conocían los conceptos de alfabetización mediática y competencias mediáticas; el total de la población dio una respuesta negativa, por lo que en la encuesta de cierre se les hizo el siguiente cuestionamiento:

- Me considero capaz de definir el concepto de alfabetización mediática y competencias mediáticas. 
Estudiantes: en esta pregunta, una gran mayoría de la población de estudiantes (81.2\%), respondió totalmente de acuerdo (20.4\%) y de acuerdo (60.8\%) en cuanto a que se consideran capaces de definir el concepto de alfabetización mediática y competencias mediáticas, mientras que $16 \%$ contestó que ni en acuerdo ni en desacuerdo, $2.2 \%$ en desacuerdo y $0.6 \%$ totalmente en desacuerdo.

Docentes: en este cuestionamiento, una gran mayoría de la población de docentes (93.8\%), respondió totalmente de acuerdo (50\%) y de acuerdo (43.8\%) en cuanto a que se consideran capaces de definir el concepto de alfabetización mediática y competencias mediáticas, mientras que $6.3 \%$ contestó ni en acuerdo ni en desacuerdo.

\section{Conclusiones}

El proyecto de intervención tuvo resultados positivos, puesto que se obtuvo evidencia de que fortaleció los perfiles de alfabetización mediática, tanto de docentes como de estudiantes, en todas las dimensiones que el Modelo AMEDES propone, es decir, en las dimensiones Tecnología, Información, Políticas TIC, Conocimiento y Comunicación. Así también, el curso permitió que los participantes comprendieran los conceptos de alfabetización y competencias mediáticas.

En cuanto a los perfiles obtenidos a partir del puntaje de cada dimensión en el cuadernillo de trabajo, se observa que se han elevado los niveles de alfabetización mediática tanto en estudiantes como en docentes.

También en los resultados de la encuesta de cierre para conocer el grado de satisfacción de los participantes en el curso, una gran mayoría de la población de estudiantes y docentes estuvo de acuerdo en cuanto a que sus conocimientos se fortalecieron en todas las dimensiones incluidas en el curso.

Con estos resultados, se puede concluir que el proyecto de intervención que se llevó a cabo mediante el Curso de Alfabetización Mediática, logró el fortalecimiento del perfil de alfabetización mediática de estudiantes y docentes de educación superior, a través de los contenidos y las actividades que permitieron generar las competencias mediáticas en los participantes.

\section{Referencias}

Altamirano, S. (2020). Modelo AMEDES. Coloquio de Investigación Educativa NMS (video). México: UANL. https://www.youtube.com/watch?v=157b5Ime Ls

APC (2005). Políticas TIC, Manual para principiantes. Uruguay: APC. https://www.apc.org/es/system/files/policy handbook ES.pdf

Armada, Y.; C. Chasco; N. Cué; M. Gómez; J. Mata (2012). Cómo buscar información académica y científica. España: Biblioteca de la Universidad de Cantabria. http://www.uv.mx/personal/ jomartinez/files/2011/08/como-buscar-en-internet 2.pdf

Diálo@os 
Belloch, C. (2013). Las Tecnologías de la Información y Comunicación (TIC). Unidad de Tecnología Educativa. España: Universidad de Valencia, 1-7. http://www.uv.es/ bellochc/pdf/pwtic1. pdf

Buckingham, D. (2015). Defining Digital Literacy: What do Young People Need to Know about Digital Media? Nordic Journal of Digital Literacy, (11), 21-34. https://www.researchgate.net/ publication/284919482

Caldevilla, D. (2010). Tipología, uso y consumo de las redes 2.0 en la sociedad digital actual. Documentación de las Ciencias de la Información, 33(7), 45-68. https://www.researchgate. net/publication/279657056 Las Redes Sociales Tipologia uso y consumo de las redes 20 en la sociedad digital actual

Celot, P.; J. Pérez (2009) Study on Assessment Criteria for Media Literacy Levels. Final Report. Bruselas: UCL, UAB, EAVI, CLEMI. http://ec.europa.eu/culture/library/studies/literacy-criteria-report en.pdf

Cornejo, M.; M. Tapia (2012). Redes sociales y relaciones interpersonales en Internet. Revista Fundamentos en Humanidades, 12(2), 219-229. Argentina: Universidad Nacional de San Luis. http://fundamentos.unsl.edu.ar/pdf/articulo-24-219.pdf

Duncan, B. et al. (1989). Media Literacy Resource Guide. Ontario Ministry of Education and the Association for Media Literacy. Toronto: Queen's Printer for Ontario.

Ferrés, J.; A. Piscitelli (2012). La competencia mediática: propuesta articulada de dimensiones e indicadores. Comunicar. Revista Científica de Comunicación y Educación, 19(38), 75-82. 10.3916/C38-2011-02-08

García, C.; M. Camacho; M. Ancona (2012). El uso de las tecnologías digitales como un proceso educativo en la sociedad del conocimiento. Revista Científica Electrónica de Educación y Comunicación en la Sociedad del Conocimiento, 1(12), 83-95. España: Universidad de Granada. https://dialnet.unirioja.es/servlet/articulo?codigo $=3973042$

González, N. (2012). Alfabetización para una cultura social, digital, mediática y en red. Revista Española de Documentación Científica, 35(monográfico), 17-45. https://doi.org/10.3989/ redc.2012.mono.976 http://redc.revistas.csic.es/index.php/redc/article/viewFile/743/824

González, N.; V. Gozálvez; A. Ramírez (2014). La competencia mediática en el profesorado no universitario, diagnóstico y propuestas formativas. Revista de Educación, (367), 117-146. http://www.educacionyfp.gob.es/revista-de-educacion/numeros-revista-educacion/numeros-anteriores/2015/367.html

Hobbs, R.; A. Jensen (2009). The Past, Present, and Future of Media Literacy Education. Journal of Media Literacy Education, 1(1), 1-11. https://digitalcommons.uri.edu/jmle/vol1/iss1/1

Hug, Th. (2013). Competencia mediática y alfabetización mediática y visual, hacia consideraciones más allá de las alfabetizaciones. Razón y Palabra, Primera Revista Electrónica en Améri- 
ca Latina Especializada en Comunicación, 82(1), 1-30. http://www.razonypalabra.org.mx/N/ N82/V82/26 Hug V82.pdf

Labrada, E. (2015). Uso del medio digital para la creación de modos comunicativos. Revista Digital Universitaria UNAM, 16(10), 1-12. http://www.revista.unam.mx/vol.16/num10/art81/ art81.pdf

Latorre, C. (2013) Competencia mediática y envejecimieto activo, Tesis. España: Universidad de La Rioja.

Livingstone, S. (2004). What Is Media Literacy? Intermedia, 32(3),18-20. http://eprints.Ise. ac.uk/1027/

Maglione, C.; N. Varlotta (2009). [e-Book] Investigación, gestión y búsqueda de información en Internet, Serie estrategias en el aula para el modelo 1 a 1. Buenos Aires: Presidencia de la Nación. https://universoabierto.org/2016/01/11/investigacion-gestion-y-busqueda-de-informacion-en-internet/comment-page-1/

Martínez, W. (2014). Técnicas de síntesis como estrategia para la comprensión lectora. Tesis de Grado. Universidad Rafael Landívar. http://recursosbiblio.url.edu.gt/tesiseortiz/2014/05/09/ Martinez-Werner.pdf

Monsalve, E.; A. Valderrama (2016). Criterios para valorar herramientas TIC para la creación de recursos educativos digitales. Colombia: Universidad de Antioquia. http://aprendeenlinea. udea.edu.co//ms/investigacion/mod/book/tool/print/index.php?id=10437-ch252

Pérez, M.; A. Delgado (2012). De la competencia digital y audiovisual a la competencia mediática: dimensiones e indicadores. Comunicar. Revista Científica de Comunicación y Educación, 20(39), 25-34. http://dx.doi.org/10.3916/C39-2012-02-02

Saiz, R. (2010). Técnicas de análisis de información, 1-6. http://es.scribd.com/doc/26836817/TECNICAS-DE-ANALISIS-DE-INFORMACION

SITEAL (2014). Políticas TIC en los sistemas educativos de América Latina, Informe sobre tendencias sociales y educativas en América Latina. http://www.siteal.iipe-oei.org/sites/default/files/siteal informe 2014 politicas tic.pdf

UNESCO (2013). Global Media and Information Literacy Assessment Framework, Country Readiness and Competencies. http://unesdoc.unesco.org/images/0022/002246/224655e.pdf

UNESCO (2005). Hacia las sociedades del conocimiento. http://unesdoc.unesco.org/ images/0014/001419/141908s.pdf 